\title{
The Lean Reference Collection: Improving Functionality through Selection and Weeding
}

\section{Christopher W. Nolan}

\begin{abstract}
Librarians expend significant amounts of money, time, and space on their reference collections, yet a surprising number state that their collections are full of materials which receive little use. Additionally, a large proportion of academic libraries do not have collection development policies for this important asset. The author discusses this problem and develops a series of guidelines for placing sources in reference, focusing especially on the suitability of the items for true reference functions and the expected frequency of use.
\end{abstract}

ibrarians implicitly assign the reference collection a high value, yet the professional literature contains little discussion of its management. ${ }^{1}$ Expenditures are the most obvious proof of this value. Librarians spend a significant percentage of library materials budgets on reference books, serials, and, increasingly, automated products. Just in terms of size, the number of titles in academic library reference collections range from a median of 5,000 titles in small college libraries to almost 30,000 titles in ARL libraries-and many of these libraries indicate that only space limitations keep these numbers from growing. ${ }^{2}$ Space devoted to a reference collection provides another tangible measure of its value. Most academic libraries assign the reference department and collection to a highly visible location, one that students and faculty will find accessible-what Mary and Victor Biggs call "highestpriority library space.'

Perhaps less tangible, but more important, is the usefulness of this collection for the provision of reference service. The reference collection is, along with the catalog, frequently the first (and sometimes only) source consulted while helping users. If the quality of reference service hinges on the resources marshaled for support, this close-at-hand collection should be critical.

Many patrons also place significant value on the reference collection. Anecdotal evidence suggests that patrons often perceive reference items to be more authoritative than those items not in reference. This logic is not difficult to follow. Reference books do not circulate, and often must even be requested at a reference desk. Librarians, asked for help answering a query, turn to some sources in reference and deliver the desired answer. Bibliographic instruction librarians demonstrate the use of indexes and provide lists of other suitable reference items. Current statistical sources are kept in reference, with earlier, outdated editions going to the stacks. All of these factors suggest to the library user that those people with expertise, the librarians, significantly value reference books.

\section{THE PROBLEM: POORLY MANAGED COLLECTIONS}

This value should have resulted in 
most libraries devising comprehensive policies for managing this resource. However, the Biggs' survey in 1985 found that only $7 \%$ of undergraduate institution libraries, $17 \%$ of masters-level libraries, and $59 \%$ of ARL libraries had written reference collection development policies. Even fewer libraries had policies for managing ready reference collections. ${ }^{4}$ Eugene A. Engeldinger found that less than $12 \%$ of academic libraries had a written policy concerning weeding of the reference collection. ${ }^{5}$

\section{Many reference librarians think their ref- erence collections are too large to be used effectively, and that it is difficult to keep track of what is in the collection and what should be updated or weeded.}

Does the absence of these policies mean that reference collections are not being managed effectively? It could be argued that other subject collection policies and procedures cover reference materials adequately. However, the Biggs' survey strongly suggested that a large number of reference collections are just too large to be used efficiently by librarians. Librarians at all types of academic libraries estimated that over $25 \%$ of the items in their reference collections had not been used in the last five years, and that half the collection was not used in the last year. ${ }^{6}$ Although these were rough estimates, they indicate that many reference librarians think their reference collections are too large to be used effectively, and that it is difficult to keep track of what is in the collection and what should be updated or weeded.

In addition to collection size, the quality of information contained therein should also be considered. If patrons and librarians frequently regard reference materials as more authoritative or valuable for answering their questions, and the collection contains seriously outdated materials, librarians may be relying on inaccurate sources. ${ }^{7}$ Gail Schlachter's short survey of reference collections and policies reported that, although most of the libraries had outdated editions of particular materials, those with reference collection development policies were more likely to provide recent (and more accurate) editions than those libraries without policies. ${ }^{8}$

\section{REASONS FOR THE PROBLEM}

Thus, many libraries, through failure to manage carefully, have created large, unwieldy reference collections which contain outdated or unused sources. Four primary factors contribute to this deficiency. First, new reference tools have proliferated over the past few years. Librarians may have been more concerned with acquiring these new sources than with determining how their coverage compares with alreadyowned sources or with weeding titles that are no longer necessary.

Second, we have not operated with a clear definition of a reference source. Responses to Marcia Bates' question "What is a reference book?" were that the definition was obvious, but also difficult to pin down-often from the same respondent. ${ }^{9}$ Merely using the basic ALA Glossary definition-that a reference book is a book used mainly for looking up definite pieces of information, rather than for continuous reading-is not sufficiently helpful because this definition is relative. ${ }^{10}$ What one reader may use only for referral-say, a commentary on the New Testament used to find information on a particular passageanother reader may read cover to cover. Likewise, librarians evaluating a new title for inclusion in the reference collection may debate whether a collection of essays with lengthy bibliographies will be used more for referral, or consecutive reading. This quandary apparently led Bill Katz to remove a very relative definition of a reference book from later editions of his standard reference textbook. ${ }^{11}$

Third, it is unclear what sorts of reference books need to be in the reference 
collection. Frequently, one librarian's "essential for reference" source is considered obscure or trivial by colleagues. Of course, this difference of opinion can occur even when a well-defined collection development policy is in force and when interpretation varies. But it is much more likely when oral tradition, rather than written policy, guides the decision.

Fourth, the nature of the reference collection hinders its effective management. Reference sources can be classified both as reference items and as items within subject disciplines. In many libraries it is unclear whether a particular reference source will be ordered by the subject bibliographer or by a reference bibliographer. It is also unclear whose responsibility it is to determine the location of the item (reference or stacks) and who weeds and evaluates the reference collection. In such situations, strong coordination of reference collection functions is necessary. Yet the compilations of collection policies in the literature show that many libraries have not clarified this role, allowing the reference collection to be neglected. ${ }^{12}$

\section{STEPS TO A SOLUTION}

Given the need for more attention to reference collections, how do we manage these issues more effectively? We will hardly be able (or want) to stem the flow of new reference sources in both traditional and electronic formats. More careful selection can avoid purchase of sources which duplicate existing items, and better book reviewing can aid careful selection. ${ }^{13}$ Creating a reference collection development policy would be a positive step toward better management. However, most of the policies in the aforementioned collections give little rationale for the entire enterprise. Instead, policies immediately launch into discussions of types of reference sources. $^{14}$

Libraries need to consider systematically what they want in their reference collections, why they want them there, and how they are placed there. This process requires five steps: first, defining more carefully what is meant by "reference source," because this is the building block of our collection; second, delineating the purposes of the reference collection; third, deciding just what types of reference sources belong in reference to achieve the best level of reference functionality; fourth, determining what makes some reference sources inappropriate for the reference collection; and fifth, clarifying administrative responsibility for the collection. Each of these steps is elaborated on below.

\section{What is a Reference Source?}

The most common definition of a reference source that appears in the published collection policies follows that already cited from the $A L A$ Glossary: a book designed to be consulted for definite items of information or a book whose use is restricted to the library building. ${ }^{15}$ The latter is, as Bates says, an administrative definition; an item is "reference" because we put it in the reference collection. ${ }^{16}$ Such administrative definitions are not particularly helpful in determining collection criteria. More helpful is the first definition. A book is a reference book because it has particular features-not defined in the Glossarythat encourage a certain form of use, i.e., consultation instead of consecutive reading.

Some have argued that a reference book is not defined by intrinsic features, but that any item a patron uses for consultation in order to find discrete bits of information can be considered a reference book. ${ }^{17}$ Certainly librarians know that users will employ almost any source in the library to find the facts they wish to locate. But a definition this relative says little about why we put particular books in reference and others in the stacks. Following this logic, we might as well categorize reference books as tools that hammer in nails or prop open doors, for some users will do these things with books. Instead, we recognize intuitively that some sources work much better for reference tasks than others. That is, a reference book is not normally read consecutively, but is con- 
sulted, and a stacks book is more likely to be read in a continuous manner. Something about reference sources distinguishes them from nonreference items.

Bates argues that the key feature of a reference book is that it consists largely of files-that is, it contains records, or information "individuals" - which are ordered according to some principle. ${ }^{18}$ These records can be further broken down into fields, or units, of data. For example, both an almanac and a bibliography arrange records into particular orders offering various access points. The arrangement of data into a file structure enhances the reader's ability to find a certain piece of information more quickly than would browsing through texts of continuous exposition.

This definition fits with the intuitive rationalizations often heard for putting an item in reference. For example, most librarians would classify an annotated bibliography of 200 pages with an introductory essay of about thirty pages as a reference book. But most would send a 200-page essay followed by a thirty-page annotated bibliography to the stacks. Why? Wouldn't both work well for finding a number of key references on a topic? Yes, but the former seems most suited for reference and the latter for circulation, precisely because the first is primarily bibliography and the latter is primarily text. That is, the first consists predominantly of files and the latter of continuous exposition. Librarians expect users to do lengthy, continuous reading only from the latter.

There are exceptions for placing books in reference, though Bates' empirical study demonstrates that these are few. Some are placed in reference for administrative reasons, most notably theftprevention. But her data demonstrated that most of the exceptions could be categorized as "authoritative texts": U.S. or state law reporters, the Bible, classic histories and treatises. ${ }^{19}$ Placing these volumes in reference appears to reflect the view that these titles are so important that users would be greatly inconvenienced by their absence from the li- brary. Also, in most cases, it is not expected that users will want to read them cover to cover. Instead, users will look up a particular Bible passage or U.S. court decision, or use the index in a monumental history to locate a key date or bit of biographical data. Thus, the reference librarian sees these sources as being used for consultation more than reading and can justify their location in reference.

Bates' study is excellent in deriving a definition of the intrinsic nature of these reference books. However, two points need further discussion. First, she states that $90 \%$ or more of all reference books could be accurately assigned to reference collections-even by a clerkassuming that the person making the decision understands how to judge a book's file structure. This statement assumes that all reference-format books belong in reference collections. But this obviously conflicts with the practices (and the few policies) of most libraries. ${ }^{20}$ Certain reference books routinely are placed in the circulating collection: superseded and outdated editions, highly specialized bibliographies, texts in languages rarely encountered by the library's clientele, etc.

Second, Bates focuses on reference books. Her discussions do not explicitly include other media of information used by reference librarians and patrons. Yet a growing number of libraries use multiple sources, most notably machinereadable files, for solving reference queries. Online databases and CD-ROM indexes, even online catalogs, serve as reference sourcés on a daily basis at many desks. Like reference books, databases are built with a logical file structure, composed of ordered records arranged in such a way as to facilitate consultation for rapid retrieval of bits of information rather than continuous reading. These online sources thus fit the definition of a reference source and should be evaluated alongside other reference sources.

However, different methods of budgeting for automated sources and, frequently, different ways of staffing for 
their use sometimes exclude consideration of these sources from the normal reference collection management process. Sheila Intner calls attention to two of the many problems which can occur when these different types of reference sources are not considered together. First, the important issue of whether an automated database can serve the users' needs more effectively or cheaply than printed sources is ignored or avoided.

The question now is which of these reference-format sources belong in the reference collection and which should be sent to the stacks or not be purchased.

Second, the automated sources often become physically separated from the remainder of the reference collection. This separation frequently occurs because of wiring problems or the convenience of sufficient space for the terminals. Thus, users attracted to the more flashy automated sources may come into less contact with reference books-and reference librarians. ${ }^{21}$ This arrangement risks either misleading users into believing that all of the important tools are computerized, or at least keeping them from learning about the variety of other sources that libraries can bring to bear on their needs.

Given that some agreement on what constitutes a reference source exists, the question now is which of these reference-format sources belong in the reference collection and which should be sent to the stacks or not be purchased. The crucial factor is how a potential source will be used. Does that use warrant adding it to the reference collection?

\section{Uses of the Reference Collection}

Patrons may use the reference collection independently, or they may be referred to particular sources by a refer- ence librarian. In either case, patrons use the collection in place of the remainder of the library's collection because they think beginning in reference seems to be more convenient or efficient than wading through the stacks. This follows logically enough from the nature of the sources housed in reference-items designed for quick consultations.

Many authors of reference textbooks classify reference sources into two basic categories according to the type of answer they provide the user: those that give the information outright, and those that tell where the desired information may be found. ${ }^{22}$ The former are often called "fact books," for they are most often compilations of facts in defined areas of interest. Of course, they may be in formats other than print, such as a CD-ROM encyclopedia. Fact books, using the reference file format, permit the user to find these discrete bits of data more efficiently than would be possible in other sources in the circulating collection.

The second type of reference source is what we might call a "pointer," for it directs the user to another source which contains the information sought. These sources are often called "bibliographic" tools, for they most frequently contain bibliographic references to items on a given topic, by a particular author, or housed in a certain collection. Periodical indexes (paper or electronic), author bibliographies, and the library's catalog are examples of this kind of source. Normally, users of bibliographic sources have at least one extra step in their search for information than do fact book users; they must look up the citation, then locate the referenced item itself.

In spite of the difference in search procedures, users of both kinds of reference sources are following similar methods. They are using reference sources as surrogates for other information sources. Fact sources summarize and abstract data originally published in other materials. Bibliographic tools also contain surrogates; for example, a citation which appears under a subject heading in a periodical index is standing for the original 
source, alerting the reader to the original's attributes.

Surrogates are not in all cases necessary, for a user could find the desired information by browsing the stacks and never using reference sources. Many users do, in fact, search in such a way. But growing collections become increasingly difficult to use when searching for a particular bit of information. Most people probably do not need a catalog for their home libraries; they can find what they want much more informally. But a collection of hundreds of thousands of volumes cannot be effectively approached the same way. Thus, as collections in libraries grew geometrically during the last century, a profusion of reference sources have also been created to serve as guides to these large collections.

The library catalog is one tool which has served almost solely as a guide to the local collection. ${ }^{23}$ However, other reference sources have always included references to materials not owned by the local library. A reference collection alerts the user to the wider information universe, not just what can be found on location. UCLA's collection development policy succinctly defines this role by indicating that the reference collection is the "key" to holdings of the local branch, the university's other libraries, and other libraries in this and other countries. ${ }^{24}$ The level at which the local reference collection supports access to this wider world of information will vary, however, with the basic philosophy of reference service and with the budget. Unlike at UCLA, for example, a small college library staff may determine that undergraduates will do just fine by using only the items owned by that library. Thus, they may acquire many fewer reference sources, avoiding those which list materials held outside their building.

But whatever the collection philosophy of the library, the reference collection must still meet its role of being an efficient guide to the larger information universe of which it is a surrogate. Convenience and ease of use by users-patrons and librarians alike-are frequently cited as ob- jectives of the reference collection. ${ }^{25}$ If the collection becomes too complex and unwieldy, users will take longer to find what they need. In the worst cases, they will not use the collection, will stick with only a few known sources, or will be defeated in their search for information. In fact, several studies indicate that users operate on the principle of "least effort"; that is, they will do as little work as necessary to find information and will often prefer information with less pertinence or authority if it is more easily available than "better" information ${ }^{26}$ Consequently, librarians must balance comprehensiveness of coverage with ease of use and avoidance of excessive complexity.

\section{Characteristics of Sources Belonging in Reference}

Books and other media sources chosen for the reference collection should be evaluated in the same manner as other acquisitions, taking into account such factors as general quality, reputation of author or publisher, and suitability for users. But the previous discussion has indicated that reference sources have a particular character and are put in reference to facilitate the rapid finding of facts or references. Based on this finding, the following characteristics should be met by titles to be added to this collection.

Librarians estimate that more than half their reference collections are not used in any one-year period and almost onethird are not used in five years.

A. Reference format. As discussed above, sources predominantly structured into files allow easier and quicker consultation. Those with mainly continuous text usually do not belong in the reference collection unless a case can be made for their convenience of use.

B. Frequently used. Librarians esti- 
mate that more than half their reference collections are not used in any one-year period and almost one-third are not used in five years. What, then, are these materials doing in reference? Surely items used less than once per year do not need to occupy space in a collection selected precisely to provide quick and convenient access. The reference stacks themselves are a file, an organized set of volumes which lead to facts or citations. Cluttering this file with rarely or never used sources merely dilutes the effectiveness of the remaining useful sources. ${ }^{27}$ Richard Dougherty writes that ARL libraries need to start weeding the dead wood out of their circulating stacks so that users may more easily find the materials they are likely to use. ${ }^{28}$ This is much more important for a reference collection. Even someone who has provided lists of many different reference titles, Constance Winchell, reminds us that the "most important element in the equipment of such a department is an adequate and live collection of reference books." 29

Many of the author's colleagues find frequency of use to be a debatable criterion. They argue that a reference collection would not be complete without certain sources, even those that fail to receive even occasional use. Yet most librarians often follow this frequent-use guideline. For instance, a good dictionary of Texas slang would probably be put into reference at a library in Texas, regardless of the size of the collection. But a small Midwestern college library would probably be less likely to do so, or perhaps would not even purchase such a volume. The determining factor is the difference in amount of expected use; the Midwestern school is probably less likely to see this item used. Implicitly, librarians do, in fact, use this criterion on occasion. What is needed is a more consistent and explicit application of it, both when a source is selected and when it is reviewed for weeding. ${ }^{30}$

Another argument contends that providing reference sources on subjects not well-represented in the general collection is cheaper and easier than trying to enlarge the circulating collection in those areas. ${ }^{31}$ Certainly the availability of items through interlibrary loan gives merit to purchasing such secondary sources. But this does not support placing them in the reference collection. On the contrary, if the subject is so peripheral that only a rare patron uses the secondary source and the collection is weak in that subject, then it would be more beneficial for that patron to have lengthier access to the source, which circulation would aid rather than hinder.

This guideline assumes that librarians can accurately judge or measure how much use the materials in reference receive. Certainly, it would be preferable to gather firm data on the use made of each item in the collection, as is sometimes possible for circulating items. A barcoded reference collection could presumably allow each item to be scanned before reshelving, thus creating the data for this analysis. More probable is that libraries which have done little previous analysis will need to do a detailed, manual use study or to have the reference librarians examine the collection and confer about perceived use patterns.

Many writers have discussed the problems associated with attempting to gauge the use of library materials. ${ }^{32}$ For example, scanning items before reshelving may underrepresent true use because many users will place the books back on the shelves themselves. However, unlike the circulating collection, the appropriateness of materials in the reference collection is frequently monitored by reference librarians who use the collection and refer patrons to it. If useful sources are removed from the reference collection, staff will receive prompt feedback about the mistakes, whether from their own searching or from patron comments. Consequently, even though some disagreement can be expected among the reference staff about perceived use, a surprising degree of consensus about those sources which have proved useless will be possible.

C. Authoritative. As mentioned above, patrons often see items in the reference collection as more authoritative than 
other sources. Further, this collection is often the sole source for librarians attempting to help their users. Thus, sources located in reference must be worthy of this reliance. In fact, this seems so obvious that some librarians wonder why it should even be necessary to mention it. ${ }^{33}$ Yet this criterion is often ignored. For example, The Gourman Report, a source which has received negative reviews for its unreliability, is routinely added to reference collections and referred to by librarians. ${ }^{34}$ No doubt many would respond that no other source fills its niche. Besides, its name recognition lends it a sort of cultural authority. But, if the critiques are valid, wouldn't a more prudent course be to leave the niche unfilled and explain to users the lack of dependable ratings services for colleges? If users will frequently choose an inferior, but more available, source of information over a more dependable source which is harder to access, selectors must be more active in their reviewing of potential reference sources and more choosy about selecting titles.

D. Current. Again, currency seems to be an obvious characteristic, one which countless policies and articles mention. However, Schlachter noted the frequency with which outdated editions reside in reference collections, and Engeldinger reported on the rarity of weeding in most collections. Of course, date of publication alone does not determine a volume's currency; its information may be as current as is needed. But the many handbooks and directories present in any collection mislead users when their data are several years old. Users may assume that the most current information is in those outdated sources, when dozens of other sources in books, articles, or online databases may be more recent and accurate.

Further, past volumes of periodical indexes or serial bibliographies are usually kept in reference. However, many of these volumes do little more than gather dust. Few users (especially students) will search more than the most recent few years of an index. Past years of in- dexes which provide coverage of contemporary reactions or styles, such as the Readers' Guide and New York Times Index, still remain quite valuable. But twenty-year-old volumes of Biological Abstracts, for example, could be moved to the stacks and perhaps be designated "noncirculating.", 35

E. Provides unique coverage. Sources should offer a distinctive contribution to locating information within their subject scope. If a source is superficial or duplicates other sources already in reference, there is little reason to add it to reference. We may all be guilty of purchasing the newest subject dictionary or statistical handbook for reference even if it duplicates others already in the collection. Of course, sometimes a particular subject area receives so much use that it becomes necessary to provide either more copies of the source or alternative sources. But the collection need not be cluttered (nor the budget encumbered) by purchasing sources which add nothing new to what is already there. An exception here would be sources which, by their nature, contain a fair amount of bias or a particular slant. For instance, Bible dictionaries written from evangelical Protestant, Catholic, and liberal Protestant perspectives may vary considerably in their definitions for certain concepts. In this case, proper coverage in the reference collection may require representative dictionaries from several major perspectives.

\section{Types of Sources that do not Belong in Reference}

Obviously not meeting the characteristics listed above would provide reasons for placing a source into the circulating collection instead of reference, i.e., not in reference format, or rarely used, unreliable, or redundant. However, librarians, citing "'oral tradition," frequently mention a few other justifications for placing sources in reference. Some of these arguments are critiqued below.

A. Requires instruction by librarian. This criterion seems to imply that because a reference source is difficult to use, it 
should be near staff members who can explain its use to patrons. But if the source is very difficult to use and is thus rarely consulted, it need not take up space in the reference collection; it does not serve well the purpose of more efficiently aiding users' research. However, if the source is essential and frequently consulted, it should be added to reference anyway. It can also be argued that the stacks are full of sources which are difficult to use, but patrons are on their own with them. If this criterion means that sources frequently mentioned in instructional sessions (and thus likely to be used) should be located in reference, then their usefulness and authority, not their difficulty of use, justify placing them in reference.

B. Protection from theft or mutilation. Occasionally a source is put in reference because it either has been stolen or mutilated in the past or that likelihood is suspected. Placement in reference presumably offers added protection. However, a reference collection created to enable efficient research and quick fact-finding does not function as well when it must dilute its file structure to become a safe haven for expensive materials. In almost all academic libraries, materials which need greater supervision than normal can be placed on reserve circulation. Theft-prone items are better placed on reserve (or in special collections rooms) than in reference.

Many libraries locate heavily-used (and thereby theft-prone) reference items in a "ready reference" collection. This approach is valid when the items already fit the reference criteria discussed earlier, but it is a waste of space and librarians' time (for retrieval, holding ID cards, etc.) when the sources are only there to prevent theft.

C. Consistency of location. All things being equal, most of us would prefer to put like sources in like locations. When we begin to purchase a monographic series of bibliographies, for instance, we often automatically add each new volume to the reference collection. However, this policy can easily lead to a bloated collection. Many of these volumes may con- cern subjects rarely pursued by the library's clientele or may be less valuable than others in the same series. Each additional item in a series should be considered individually according to the accepted set of criteria. An exception to this would be a series in which one volume refers to other volumes in the same set, such as the Dictionary of Literary Biography.

D. Fills a niche. Reference librarians usually applaud a new publication which covers an area previously neglected. Impressed as we are by wellmade reference tools, we tend to put these items into the reference collection because "we don't have anything else on that subject." However, most subjects will be covered in a general reference collection by at least the broader sources, such as encyclopedias and guides to the literature. The new source should be evaluated by the other criteria, especially expected frequency of use. A source filling a small niche, however nicely done and unique, should be sent to the circulating stacks if very little demand is expected.

E. "Classic" source. Finally, there are those sources which one or more librarians (or sometimes patrons) believe must be in any quality reference collection. Some of these tools have earned this status by years of productive service to librarians, and they may indeed be essential acquisitions. Others exhibit superior writing or editorial design. But each library's collection serves a different set of user needs, and a source much used at one institution may have little use at another. If it is rarely needed, it probably should be located in the stacks collection. These titles should be purchased for the general collection if they fit into the library's collection policies. If they become more valuable as a curriculum changes or subject interests shift, they can at that time be moved to reference.

\section{Administrative Responsibility for the Reference Collection}

A perusal of reference collection development policies shows that various systems of selecting and supervising the 
collection are practiced. Rebecca Kroll lists a few of the people that usually select the reference sources for the collection, ranging from the subject bibliographer, who does not work in reference, to the reference subject specialist. She also lists the people who most frequently function as the managers of this process, including heads of reference, coordinators for reference collection development, and committees of reference librarians. $^{36}$

However, both the noted lack of collection development policies for reference and the comments of many colleagues indicate that oversight for the reference collection is often lacking or poorly defined. A major reason for this confusion is that reference sources may be classified both as subject materials and as reference-format sources. Because most academic libraries divide responsibility for materials selection by discipline, overlaying further responsibilities by type of material can be difficult. Many problems result from a lack of careful management.

First, the assignment of selection for a discipline to just one individual bibliographer allows the idiosyncrasies of that selector to color the makeup of the collection. Imbalanced selection, especially excessive additions to areas not calling for such build-up, is possible without oversight. Second, sources which do not fit neatly into a division of responsibility by subject disciplines may be missed by selectors who assume another librarian will order them. For example, interdisciplinary items and general items (such as almanacs and biographical sources) often defy easy categorization by subject. Third, selection may occur in the absence of feedback concerning the use made of the collection by patrons and staff. This situation is especially likely when librarians who may spend little or no time with the library's clientele, such as subject bibliographers or heads of reference, are responsible for adding to and weeding out the reference materials.

The first two problems both stem from the lack of someone overseeing the entire reference selection and deselection process. The most obvious solution would be the appointment of an individual or committee to ensure that the selectors properly address the entire scope of the reference collection and that the collection is balanced within the framework of a reference collection development policy's goals. This person or committee must have the authority to allocate funds directly from a reference account and also to question perceived errors of selection or weeding by the various reference selectors. This position need not have the power to prevent the other selectors from ordering items they would like to add to reference, but it should have the ability to refer the discussion of adding these materials to an assigned point of resolution (e.g., the head of reference).

Whether a committee or a designated librarian has the authority for these decisions is not as important as is the explicit designation of someone to take charge of the process. Libraries cannot continue to allow a variety of individuals to make haphazard decisions about what the reference collection should be.

The third problem exists when the persons making decisions about reference materials have little knowledge of the uses made of the collection. In academic libraries with several staff members serving at the reference desk, it is impossible for any single librarian to have a complete picture of the use made of the collection. Thus, it is important to set up a formal mechanism for discussing appropriate titles to add or weed. The best scenario would include regular reference staff meetings to consider individual reference sources for addition or deselection and to voice staff experiences in working with patrons who use those types of materials. These meetings would not only provide better feedback about selecting good reference sources, 
but would also serve as a form of continuing education. If staff size makes this an unwieldy process, a committee of several librarians with varied subject expertise might be the best alternative.

Whether a committee or a designated librarian has the authority for these decisions is not as important as explicitly designating someone to take charge of the process. Libraries cannot continue to allow a variety of individuals to make haphazard decisions about what the reference collection should be. The reference collection must be actively managed to meet the goals and objectives determined by the reference department.

\section{CONCLUSION}

Reference collections serve as subsets of, or surrogates for, the larger world of information and thereby permit users to search for the information they desire in a more efficient and convenient manner. This situation requires reference to be a highly functional collection of appropriately chosen sources, including as many as necessary to meet normal user needs while avoiding excessive complexity.
However, the reviewed literature demonstrates that librarians admit to the existence of cluttered, overgrown collections which are all too infrequently guided by well-reasoned collection development policies.

Consequently, it is imperative that those librarians responsible for selection and management of reference collections do two things: first, apply more rigorous thought to the criteria for determining what gets located in those collections; and second, review the collection on a regular, systematic, and aggressive basis in order to determine which sources are appropriate and which merely occupy space and dilute the useful materials. It is possible that the vast majority of reference collections would be significantly diminished in size if these proposed guidelines were actively followed. ${ }^{37}$ This, however, will not diminish the effectiveness of those collections. Instead, the leaner, trimmer collection will become more functional; users will find useful sources more easily; and librarians can reclaim valuable space which can be put to other uses.

\section{REFERENCES AND NOTES}

1. Lynn C. Hattendorf, "The Art of Reference Collection Development," RQ 29:219-20 (Winter 1989).

2. Mary Biggs and Victor Biggs, "Reference Collection Development in Academic Libraries," $R Q$ 27:69-70 (Fall 1987).

3. Ibid., p.74.

4. Ibid., p.70-71.

5. Eugene A. Engeldinger, "Weeding of Academic Library Reference Collections: A Survey of Current Practice," RQ 26:367 (Spring 1986).

6. Biggs and Biggs, "Reference Collection Development," p.74-75.

7. Rebecca Kroll, "The Place of Reference Collection Development in the Organizational Structure of the Library," $R Q$ 25:99 (Fall 1985).

8. Gail Schlachter, "Obsolescence, Weeding, and Bibliographic Love Canals," RQ 28:7-8 (Fall 1988).

9. Marcia J. Bates, "What Is a Reference Book? A Theoretical and Empirical Analysis," $R Q$ 26:40 (Fall 1986).

10. Heartsill Young, ed., The ALA Glossary of Library and Information Science (Chicago: American Library Assn., 1983), p.188.

11. William A. Katz, Introduction to Reference Work, 2v. (New York: McGraw-Hill, 1969), 1:12, and also 5 th ed., 1987.

12. For examples, see Bill Katz, ed., Reference and Online Services Handbook: Guidelines, Policies, and Procedures for Libraries (New York: Neal-Schuman, 1986), V.2, and Paula D. Watson, ed., Refer- 
ence Policy and Administrative Documents (Chicago: Reference and Adult Services Division, American Library Assn., 1985), p.562-781.

13. Gail Schlachter, "Reviewing the Reviewers," RQ 27:468-70 (Summer 1988).

14. Interestingly, this process mirrors the structure of reference courses in many library schools, in which most of the courses are spent discussing and using particular reference sources, but little time is devoted to analyzing the reference interview, reference management, and other theoretical issues.

15. Young, ALA Glossary, p.188.

16. Bates, "What Is a Reference Book?" p.38.

17. For example, see Donald Edward Davinson, Reference Service (London: Clive Bingley, 1980), p.12-13.

18. Bates, "What Is a Reference Book?" p.41-43.

19. Ibid., p.51-53.

20. Biggs and Biggs, "Reference Collection Development," p.72.

21. Sheila S. Intner, "A Question of Medium," Technicalities 7:13-14 (Oct. 1987).

22. For example, see Archie G. Rugh, "Toward a Science of Reference Work: Basic Concepts, "RQ 14:293-99 (Summer 1975).

23. This is rapidly changing because many library online catalogs now contain bibliographic references to information, such as commercial periodical databases, not held in the local library.

24. UCLA's policy is reprinted in part in Watson, Reference Policy, p.583.

25. Cf. A. R. Spofford, "Works of Reference for Libraries," in Public Libraries in the United States of America: Their History, Condition and Management (Washington, D.C.: GPO, 1976), p.687-88, and Engeldinger, "Weeding," p.371.

26. See Herbert Poole, Theories of the Middle Range (Norwood, N.J.: Ablex, 1985), p.86-92; Esther G. Bierbaum, "A Paradigm for the '90s," American Libraries 21:18-19 (Jan. 1990); and Winifred Sewell and Sandra Teitelbaum, "Observations of End-User Searching Behavior over Eleven Years," Journal of the American Society for Information Science 37:239-40 (July 1986).

27. Cf. Duke University's policy reprinted in Watson, Reference Policy, p.610.

28. Richard M. Dougherty, "Ridding Collections of Deadwood," Journal of Academic Librarianship 15:3 (Mar. 1989).

29. Constance M. Winchell, Guide to Reference Books, 8th ed. (Chicago: American Library Assn., 1967), p.xiv (emphasis added).

30. The Georgia Institute of Technology policy, emphasizing this criterion, is reprinted in Katz, Reference and Online Services Handbook, 2:117-18.

31. Ruth C. Hale, "Academic Library Reference Collection Policy Statements: An Informed Consideration," in Katz, Reference and Online Services Handbook, 2:27.

32. See Daniel R. Arrigona and Eleanor Mathews, "A Use Study of an Academic Library Reference Collection," $R Q$ 28:71-81 (Fall 1988). Classic discussions of use studies include Robert N. Broadus, "Use Studies of Library Collections," Library Resources \& Technical Services 24:317-24 (Fall 1980); Allen Kent and others, Use of Library Materials: The University of Pittsburgh Study (New York: Dekker, 1979); and Paul Metz, The Landscape of Literatures: Use of Subject Collections in a University Library (Chicago: American Library Assn., 1983).

33. Fred Batt, "The Detailed Reference Collection Development Policy: Is it Worth the Effort?" in Bill Katz and Ruth A. Fraley, eds., Evaluation of Reference Services, The Reference Librarian, no. 11 (New York: Haworth, 1984), p.319.

34. David S. Webster, "Jack Gourman's Rankings of Colleges and Universities: A Guide for the Perplexed," RQ 25:323-31 (Spring 1986).

35. This procedure is described in the Texas A\&M policy included in Katz, Reference and Online Services Handbook, 2:214.

36. Kroll, "The Place of Reference Collection Development," p.96-99.

37. Cf. the major reduction in the size of a reference collection following a careful review reported in Paul T. Adaliar, Jr., and Ilene F. Rockman, "Title-by-Title Review in Reference Collection Development," Reference Services Review 12:85-88 (Winter 1984). 
Middle Ages Series

\section{A Tainted Mantle}

Hercules and the Classical Tradition at the Carolingian Court

Lawrence Nees

Mar. 1991. $392 \mathrm{pp}, 3$ color \& $88 \mathrm{~b} / \mathrm{w}$ illus. Cloth, 8216-7, \$39.95

From Ad Hoc to Routine

A Case Study in Medieval Bureaucracy Ellen E. Kittell

Apr. 1991. 256 pp, 9 illus. Cloth, 3079. 5, $\$ 35.95$ (tent.)

Literature

Macropolitics of Nineteenth-

Century Literature

Nationalism, Exoticism, Imperialism

Edited by Jonathan Arac \& Harriet Ritvo New Cultural Studies Series.

Feb. 1991. 320 pp. Cloth, 8208-6, \$34.95

Lyric Contingencies

EmilyDickinson and Wallace Stevens Margaret Dickie

Feb. 1991. 208 pp. Cloth, 3077-9, \$23.95

American Designs

The Late Novels of James and Faulkner Jeanne Campbell Reesman

Apr. 1991. 232 pp. Cloth, 8253-1, $\$ 25.95$ (tent.)

Social Sciences

Feedback Thought in Social

Science and System Theory

George P. Richardson

Mar. 1991. 380 pp. Cloth, 3053-1,

\$39.95; paper, 1332-7, \$19.95 (tent.)
Anthropology/Folklore

Ethics and the Profession of Anthropology

Dialogue for a New Era

Edited by Carolyn Fluehr-Lobban

Feb. 1991. 256 pp. Cloth, 8157-8, \$31.95

Rhetorics and Politics in Afghan

Traditional Storytelling

Margaret A. Mills

Publication of the American Folklore Society.

Mar. 1991. 288 pp. Cloth, 8199-3,

$\$ 27.95$ (tent.)

Law

Planning for Serfdom

Legal Economic Discourse and

Downtown Development

Robin Paul Malloy

May 1991. 232 pp. Cloth, 3055-8,

$\$ 27.95$ (tent.)

International Law and Pollution

Edited by Daniel Barstow Magraw

Apr. 1991. 416 pp. Cloth, 3053-1,

\$37.95 (tent.)

History of Science

The Literary Structure

of Scientific Argument

Edited by Peter Dear

Feb. 1991. 208 pp, 6 illus. Cloth, 8185 .

3, $\$ 28.95$

The Japanese and Western Science

Masao Watanabe

Translated by Otto Theodor Benfey

Apr. 1991.128 pp, 45 illus. Cloth, $8252-3, \$ 28.95$ (tent.)

\section{University of Pennsylvania Press}

P.O. Box 4836, Hampden Station, Baltimore, MD 21211 Toll-free: (800) 445-9880 